\title{
A standardized repair-oriented strategy for mitral insufficiency in infants and children: Midterm functional outcomes and predictors of adverse events
}

\author{
David Kalfa, MD, PhD, Mathieu Vergnat, MD, Mohamedou Ly, MD, Bertrand Stos, MD, \\ Virginie Lambert, MD, PhD, Alban Baruteau, MD, and Emre Belli, MD
}

\begin{abstract}
Objective: Surgical management of mitral regurgitation (MR) in children remains a challenge because of the heterogeneity of the anatomy, growth potential, and necessity to avoid valve replacement. Our objective was to assess the functional outcomes and prognostic factors of a standardized strategy of mitral valve (MV) repair for children with MR.
\end{abstract}

\begin{abstract}
Methods: Consecutive patients aged $<18$ years who had undergone surgery for severe MR from 2001 to 2012 were studied retrospectively. The standardized repair strategy mainly included leaflet debridement, annuloplasty, and leaflet augmentation. Multivariable risk analyses for recurrent MR (grade > II), transmitral mean echocardiographic gradient $>5 \mathrm{~mm} \mathrm{Hg}$, MV reoperation, replacement, and mortality were performed.
\end{abstract}

\begin{abstract}
Results: A total of 106 patients were included (median age, 5.1 years; range, 11 days to 18 years). The mean follow-up period was $3.9 \pm 3.2$ years (range, 2 months to 11 years). The proportion of congenital and left heart obstruction-related (left ventricular outflow tract obstruction) etiology was $49 \%(\mathrm{n}=52)$ and $11 \%(\mathrm{n}=12)$, respectively. MV repair was performed primarily in $97 \%$ of the patients. The mortality, reoperation, replacement, and MR rate at the last follow-up visit was $4.5 \%(\mathrm{n}=5), 23 \%(\mathrm{n}=24), 5.5 \%(\mathrm{n}=6)$, and $17 \%(\mathrm{n}=18)$, respectively. Actuarial survival was $93 \% \pm 2 \%$ at 10 years. Freedom from MV replacement was $95 \% \pm 2 \%$ and $86 \% \pm 7 \%$ at 5 and 15 years, respectively. Native valve preservation was obtained in $85 \%$ of the infants and $94 \%$ beyond infancy. Independent predictors of recurrent MR, MV reoperation, and replacement included left ventricular outflow tract obstruction etiology (hazard ratio, 45; $P=.004$ ), associated preoperative mitral stenosis (hazard ratio, 21; $P=.03$ ), and young age (hazard ratio, $1.2 ; P=.04$ ).

Conclusions: A standardized and reproducible MV repair strategy can achieve satisfactory functional results in infants and children with severe MR, allowing native valve preservation. The left ventricular outflow tract obstruction-related etiology was the main independent predictor of recurrent MR, MV reoperation, and MV replacement. (J Thorac Cardiovasc Surg 2014;148:1459-66)
\end{abstract}

Surgical management of mitral regurgitation (MR) in the pediatric population remains a challenge because of the heterogeneity of the lesions, requirement for growth potential, and necessity of avoiding mitral valve (MV) replacement. Various nonstandardized repair techniques have been reported in children with congenital MV disease, demonstrating the benefits of MV repair versus replacement. ${ }^{1-11}$ Nevertheless, these series have reported variable outcomes, related to the small size and heterogeneity of

\footnotetext{
From the Department of Pediatric and Congenital Heart Disease, Marie Lannelongue Hospital, University Paris Sud, Centre de Référence Nationale des Malformations Cardiaques Congénitales Complexes, "M3C," Le Plessis-Robinson, France. Disclosures: Authors have nothing to disclose with regard to commercial support. Presented at The 2013 American Association for Thoracic Surgery Mitral Conclave, New York, New York, May 2, 2013.

Received for publication Sept 15, 2013; revisions received Jan 17, 2014; accepted for publication Feb 19, 2014; available ahead of print March 22, 2014

Address for reprints: Emre Belli, MD, Department of Pediatric and Congenital Heart Disease, Centre Chirurgical Marie Lannelongue, 133 Av de la Résistance, Le Plessis-Robinson 92350, France (E-mail: e.belli@ccml.fr). $0022-5223 / \$ 36.00$

Copyright (c) 2014 by The American Association for Thoracic Surgery http://dx.doi.org/10.1016/j.jtcvs.2014.02.057
}

the studied population and the variability of the surgical techniques performed at each center. Moreover, the predictors of adverse events in this surgically challenging pediatric population are still lacking in the published data, essentially because of the relative paucity of this condition and the subsequent limited number of patients previously reported in studies.

Our unit implemented a "nothing else but repair" strategy in which a standardized procedure on the MV was performed in all cases, ideally restoring durable, functional anatomy. The present study aimed at describing the features of this repair-oriented strategy, reporting the midterm functional outcomes, and determining the predictors of MV-related adverse events.

\section{METHODS \\ Patients \\ The echocardiograms, medical records, and operative reports for all patients aged $<18$ years who had been referred to our institution for surgical treatment of severe mitral insufficiency (MI) from 2001 to 2012 were retrospectively reviewed. A total of 106 patients were included. The median age at surgery was 5.1 years (range, 11 days to 18 years).}




\section{Abbreviations and Acronyms \\ $\mathrm{CI}=$ confidence interval \\ HR = hazard ratio \\ $\mathrm{LV} \quad=$ left ventricular \\ LVOTO $=$ left ventricular outflow tract obstruction \\ MI = mitral insufficiency \\ MR $=$ mitral regurgitation \\ MV = mitral valve}

Of the 106 patients, $30(25 \%)$ were $<1$ year and $41(38.6 \%)$ were $<2$ years old (Figure 1). All patients presented with symptoms, including failure to thrive and intolerance to feeding in infants and young children, and New York Heart Association class III-IV in the older patients. The 4 most frequent etiologies of MR were congenital $(n=52 ; 49 \%)$, including the presence of a mitral leaflet cleft $(n=15 ; 14 \%)$, rheumatic $(n=13$; $12 \%$ ), related to left ventricular (LV) outflow tract obstruction (LVOTO; $\mathrm{n}=12 ; 11 \%)$, and ischemic ( $\mathrm{n}=11 ; 10 \%$; in 10 , an anomalous left coronary artery arising from the pulmonary artery, and in 1, atresia of the left coronary ostium). Twelve patients $(11 \%)$ had associated mitral stenosis, defined by a mean echocardiographic gradient of $>10 \mathrm{~mm} \mathrm{Hg}$. Most patients had an associated lesion in addition to MR. Patients presenting with repaired atrioventricular septal defect were excluded. The patient and mitral valve anatomic and functional characteristics are listed in Table 1 and the functional classification in Table 2.

\section{Echocardiographic Evaluation}

All 106 patients had undergone an echocardiographic examination before surgery, during surgery (control transesophageal echocardiography), at discharge from the hospital, and annually during the follow-up visits. Preoperative MV function was assessed by transthoracic echocardiography according to the European Association of Echocardiography guidelines. ${ }^{12}$ In brief, the echocardiographic examinations were used to assess the MV anatomy and function (ie, annulus, leaflet, subvalvar apparatus), quantified the MR (ie, size of the left cavities using M mode, reverse flow in the pulmonary veins using pulsed Doppler, and proximal isovelocity surface area), and evaluate the consequences of MR (ie, LV ejection fraction using Simpson's method, systolic pulmonary artery pressure calculated from the tricuspid regurgitation flow velocity, mean pulmonary artery pressure calculated from the pulmonary regurgitation flow velocity). A multimodality approach combining all these parameters was used to separate MR into 4 classes from I to IV. Preoperatively, 54 patients $(51 \%)$ had moderate to severe MR (grade III) and $44(42 \%)$ had severe (grade IV) MR.

\section{Surgical Technique}

After median sternotomy and pericardotomy, cardiopulmonary bypass was established using standard aortic and bicaval cannulation, antegrade intermittent warm blood cardioplegia, and normothermia. A patch of pericardium was prepared free from adipose and extrapleural tissue and treated in glutaraldehyde for 7 minutes in the primary procedures.

After dissection of Sondergaard's groove, a left atriotomy was performed. Annular stay stitches were placed on both trigones and posterior part of the annulus to expose the MV. Direct and systematic inspection of the MV apparatus (ie, papillary muscles, chordae, leaflets, and annulus) using nerve hooks allowed us to confirm the echocardiographic findings and completely assess the valve pathologic condition and MR mechanism and etiology.

A 3-step standardized repair strategy was then applied, leading to surgical interventions according to the MR mechanism and etiology and
MV anatomy. The final objective of this standardized repair strategy was to restore the functional MV anatomy to as close as possible to the normal functional anatomy.

Step A. The first step consisted of subvalvular apparatus rehabilitation, mainly to increase the leaflet mobility through extensive leaflet debridement. This step, involving both leaflets and using nerve hooks to expose the lesions, required

1. Searching for and cutting all useless and restrictive secondary chordea tendinae

2. Splitting the papillary muscles in the case of shortened leaflets or "papillary muscle-leaflet fusion"

3. In the case of leaflet prolapse, shortening the papillary muscle, directly or by intraventricular repositioning, chordae transfer, and/or the use of artificial PTFE chordae or resection of redundant anterior leaflet tissue associated with repositioning of a native chordae coming from the anterior or posterior leaflet

Twenty patients $(19 \%)$ benefitted from the latter technique. The treatment of posterior leaflet prolapse was performed by quadrangular resection of the posterior leaflet associated with sliding plasty of each hemileaflet $(\mathrm{n}=9 ; 8 \%)$. Step A was required in more than two thirds of the patients $(\mathrm{n}=75 ; 71 \%)$.

Step B. Step B consisted of plication and reinforcement of the mitral annulus. The 3 tools were used to meet this aim were as follows:

1. Commissural and posterior annuloplasty stitches, in younger patients and larger patients, in the case of insignificant annular dilatation. This procedure was used in 15 patients $(14 \%)$.

2. Posterior annuloplasty, using a Gore-Tex Accuseal interrupted strip (W. L. Gore \& Associates, Inc, Flagstaff, Ariz), in the case of severe annular dilatation in growing children. This strip should be sutured to the posterior annulus using mattress sutures, extending a few millimeters over each trigon. Stitches placed on the annulus will unequally plicate different segments of the posterior annulus, especially at the level of each trigone and the level of P3 in LVOTO-related and ischemic MR. The Accuseal strip should be cut in a semicircular fashion, with a length corresponding to approximately two thirds of the Rowlatt table-based indexed annulus size. Additional resorbable polydioxanone annuloplasty sutures to allow further growth of the annulus at a distance from the surgery has also been occasionally used. Posterior annuloplasty was used in 50 patients $(47 \%)$.

3. Complete annuloplasty, using a prosthetic ring, in the case of severe dilatation when $\mathrm{a} \geq 28 \mathrm{~mm}$ prosthetic ring was suitable. The ring should

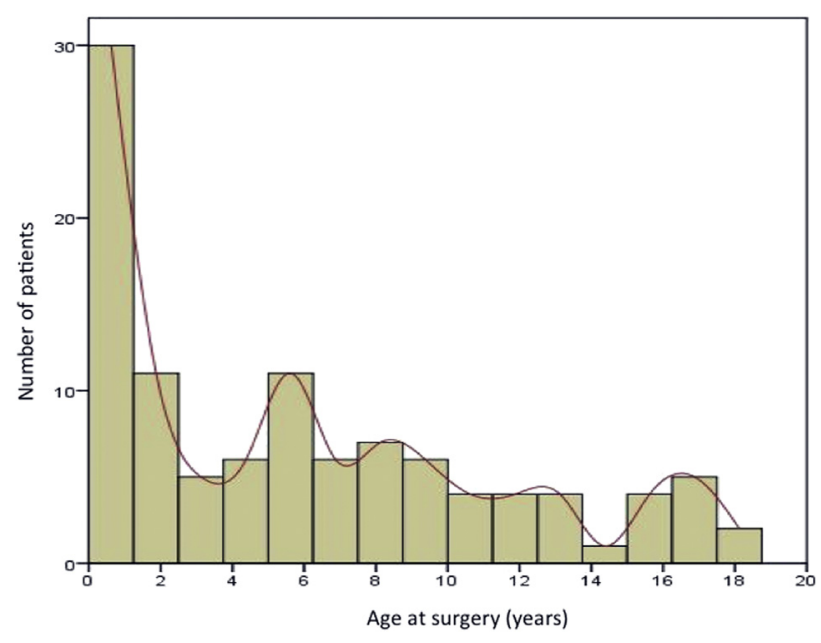

FIGURE 1. Age at surgery stratified by the number of patients. 
TABLE 1. Patient and mitral valve characteristics

\begin{tabular}{|c|c|}
\hline Characteristic & Value \\
\hline \multicolumn{2}{|l|}{ Patient demographic data } \\
\hline \multicolumn{2}{|l|}{ Age at surgery } \\
\hline Median (y) & 5.1 \\
\hline Range & $11 \mathrm{~d}$ to 18 \\
\hline \multicolumn{2}{|l|}{ Weight at surgery $(\mathrm{kg})$} \\
\hline Median & 16 \\
\hline Range & $3-79$ \\
\hline Male gender & $50(47)$ \\
\hline \multicolumn{2}{|l|}{ Preoperative cardiac functional status } \\
\hline NYHA class III-IV & $106(100)$ \\
\hline Preoperative LV dysfunction $(\mathrm{EF}<50 \%)$ & $24(22)$ \\
\hline Preoperative artificial ventilation & $6(6)$ \\
\hline Previous cardiac surgery in another hospital & $22(21)$ \\
\hline \multicolumn{2}{|l|}{ Mechanisms of MR (Carpentier's functional classification) } \\
\hline $\begin{array}{l}\text { Type I, normal leaflet motion (isolated cleft } \\
\text { or annular dilatation) }\end{array}$ & $47(44)$ \\
\hline Type II, enhanced leaflet motion (isolated leaflet prolapse) & $24(23)$ \\
\hline Type III, restricted leaflet motion & $35(33)$ \\
\hline Restricted leaflet motion with normal papillary muscles & 27 \\
\hline Short chordae & 25 \\
\hline Thickened leaflets & 22 \\
\hline Fused commissures & 18 \\
\hline Papillary muscle-commissural fusion & 12 \\
\hline Accessory MV tissue & 7 \\
\hline Valvular ring & 1 \\
\hline $\begin{array}{l}\text { Restricted leaflet motion with abnormal } \\
\text { papillary muscles }\end{array}$ & 8 \\
\hline Papillary muscle hypoplasia & 4 \\
\hline Hammock valve & 3 \\
\hline Parachute valve & 1 \\
\hline Associated stenotic component & 12 \\
\hline \multicolumn{2}{|l|}{ MR etiology } \\
\hline Congenital, other than isolated anterior mitral leaflet cleft & $37(35)$ \\
\hline Isolated anterior mitral leaflet cleft & $15(14)$ \\
\hline Rheumatismal & $13(12)$ \\
\hline Left heart obstruction-related & $12(11)$ \\
\hline Ischemic & $11(10)$ \\
\hline \multicolumn{2}{|l|}{ Other } \\
\hline Marfan syndrome & 5 \\
\hline Endocarditis & 5 \\
\hline Iatrogenic & 5 \\
\hline Barlow disease & 2 \\
\hline Dilated cardiomyopathy & 1 \\
\hline Associated lesions addressed at procedure & $57(54)$ \\
\hline LVOTO & $9(8)$ \\
\hline Anomalous left coronary artery from pulmonary artery & $9(8)$ \\
\hline Atrial septal defect & $7(7)$ \\
\hline Complex cyanotic cardiac defects & $7(7)$ \\
\hline Tricuspid regurgitation & $6(6)$ \\
\hline Aortic regurgitation & $6(6)$ \\
\hline Other & $8(8)$ \\
\hline Marfan syndrome & $5(5)$ \\
\hline
\end{tabular}

Data presented as $\mathrm{n}(\%)$, unless otherwise noted. NYHA, New York Heart Association; $L V$, left ventricular; $E F$, ejection fraction (Simpson); $M R$, mitral regurgitation; $M V$, mitral valve, $L V O T O, \mathrm{LV}$ outflow tract obstruction. be appropriately sized to the surface area of the anterior leaflet. Complete annuloplasty was used in 19 patients (18\%). No absorbable annuloplasty device was used.

Step C. The goal of step C was to improve leaflet coaptation, through leaflet augmentation with an autologous pericardial patch. Anterior leaflet augmentation $(\mathrm{n}=19 ; 18 \%)$ was progressively preferred to posterior augmentation $(\mathrm{n}=7 ; 6 \%)$ and was sutured using a running suture secured by some single stitches to avoid dramatic patch dehiscence. The patch was sized to obtain adequate coaptation at testing, with the aim of avoiding excessive redundant tissue. The patch was usually placed close to the normal mitral valve surface. This repair was performed in the case of obvious leaflet tissue retraction or nonoptimal leaflet coaptation after steps A and B. In primary procedures, glutaraldehyde-treated autologous pericardium was preferred, and, in the redo environment, more likely fresh autologous pericardium was preferred. In our early experience, we chose posterior leaflet augmentation from 1 commissure to the other. However, this technique resulted in a significant and progressive postoperative transvalvular gradient, particularly in infants, obviously because of the "gutter effect." At present, the indications for posterior leaflet augmentation have been limited to some relatively larger patients presenting with LVOTO-related and ischemic MR, and the leaflet augmentation will involve the posterior two thirds of the leaflet, with the anterior scallop preserved (Figure 2).

The results of this repair strategy were then assessed by saline injection through the valve, taking care to not damage the LV endocardium and to perform perioperative transesophageal echocardiography. Revision will be required in the case of nonadequate hemodynamics or a nonoptimal immediate postoperative result, defined as an MR grade of II or III and/or a mean echocardiographic gradient $>5$ to $8 \mathrm{~mm} \mathrm{Hg}$, depending on patient age.

Of the 106 patients, 3 did not undergo primary MV repair. Two had been transferred from North Africa to our institution with a predetermined indication for MV replacement; the third patient had extremely severe MR, with crumbly and tearing leaflet tissue, preventing the surgeon from suturing it.

MV repair was associated with another cardiac procedure in 43 patients ( $40 \%$; Table 2$)$. The mean cardiopulmonary bypass and aortic clamping time was $105 \pm 46$ and $75 \pm 34$ minutes, respectively.

\section{Follow-up}

Since 2001, all patients have undergone examination at least yearly, including a clinical assessment, an electrocardiogram, and a 2-dimensional echocardiogram with color Doppler study performed by the institutional or referring cardiologist. Clinical and echocardiographic mitral functional status and number of reoperations at the most recent follow-up point were obtained from local medical records or the primary referring cardiologist. The mean follow-up period was $3.9 \pm 3.2$ years (range, 2 months to 11 years), and the data were complete at $100 \%$. The end of the follow-up period was November 2012.

\section{Data Collection and Statistical Analysis}

The endpoints studied at most recent follow-up visit were recurrent MR (defined as grade II-III), a transmitral mean echocardiographic gradient $>5 \mathrm{~mm} \mathrm{Hg}$, MV reoperation, MV replacement, and mortality. Statistical analysis was performed using PASW Statistics, version 17.02, software (IBM SPSS Inc, Armonk, NY). Data are expressed as the median and range or mean \pm standard deviation. The comparison of percentages and mean and median values was achieved with the chi-square test or Fisher's exact test for dichotomous variables and the Student $t$ test or nonparametric Mann-Whitney $U$ test for continuous variables. Actuarial freedom from MV reoperation, replacement, and mortality was analyzed using the 
TABLE 2. Outcomes according to mechanism and etiology of mitral valve insufficiency

\begin{tabular}{lccccc}
\hline $\begin{array}{c}\text { MI mechanism (Carpentier's } \\
\text { classification) and MI etiology }\end{array}$ & Cardiac death & Reoperation & Replacement & $\begin{array}{c}\text { Occurrence of MI grade } \\
>\mathbf{2} \text { during follow-up }\end{array}$ & $\begin{array}{c}\text { Occurrence of mitral mean } \\
\text { echocardiographic gradient } \\
>\mathbf{1 0 ~ m m ~ H g ~ d u r i n g ~ f o l l o w - u p ~}\end{array}$ \\
\hline Type I & 2 & 11 & 1 & 16 & 3 \\
Typetal
\end{tabular}

MI, Mitral insufficiency; LVOTO, left ventricular outflow tract obstruction.

Kaplan-Meier estimates with $95 \%$ confidence intervals. Univariate analysis of time-related events was achieved using the log-rank test and the univariate Cox model, which allowed the selection of variables $(P<.10)$ for inclusion in the multivariate analysis. The multivariate analysis was performed using a logistic regression model to estimate the risk factors for recurrent MR and transmitral gradient and a Cox model to estimate the risk factors for MV reoperation, MV replacement, and mortality. The variables were included in the model by backward elimination if $P<.05$.

\section{RESULTS}

\section{Mortality, Reoperations, Replacements, and MV Functional Status}

Four patients underwent revision of the initial MV repair in the same anesthetic session after transesophageal echocardiography. Three in-hospital deaths (3\%) occurred. A 10-month-old boy died of multiorgan failure after $1 \mathrm{MV}$ repair for MV endocarditis. A newborn girl with severe congenital MR, severe LV dysfunction, and preoperative artificial ventilation died of low cardiac output after 2 attempts at MV repair. A 4-month-old boy initially had

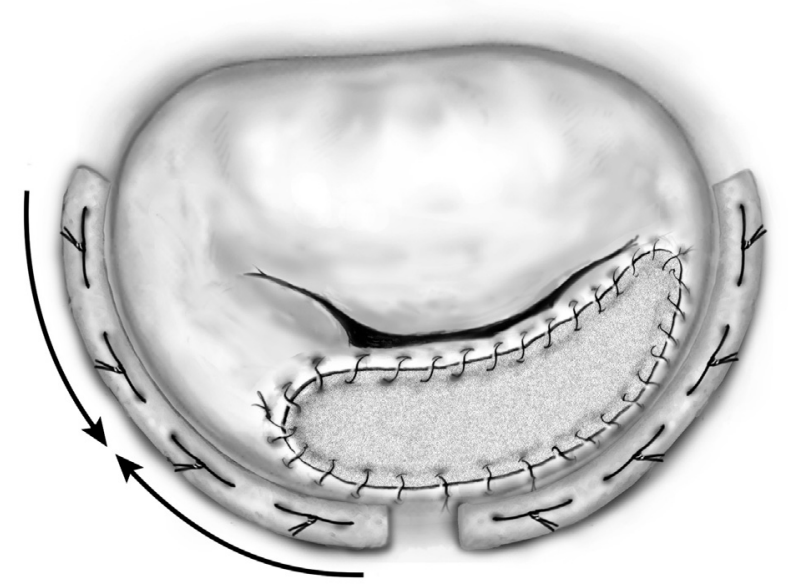

FIGURE 2. Subtotal posterior leaflet augmentation, avoiding the "gutter" effect, and interrupted annuloplasty. congenital stenosis of the main left coronary artery. He had undergone coronary artery bypass grafting at another institution but then presented with severe MR and LV dysfunction requiring 3 consecutive MV replacements. He finally died of prosthetic valve dysfunction.

At discharge, 4 patients had residual moderate-to-severe (grade III) MR; all others had no MR or grade I-II MR. Three patients required a definitive pacemaker because of associated non-MV-related surgical procedures. During the follow-up period, 24 patients $(23 \%)$ underwent 31 MV reoperations (25 repairs and 6 replacements). The indications for $\mathrm{MV}$ reoperation were progressive $\mathrm{MR}$ $(\mathrm{n}=16)$, progressive mitral stenosis $(\mathrm{n}=4)$, severe valve-related hemolysis $(n=3)$, repair rupture $(n=2)$, late reopening of a mitral cleft $(n=2)$, endocarditis $(\mathrm{n}=2)$, iatrogenic catheter-induced MV perforation $(\mathrm{n}=1)$, and severe calcification of the anterior leaflet augmentation patch $(\mathrm{n}=1)$. Six of these patients $(6 \%)$ finally required MV replacement with $17-\mathrm{mm}(\mathrm{n}=1)$, 19-mm $(\mathrm{n}=1), 23-\mathrm{mm}(\mathrm{n}=2), 25-\mathrm{mm}(\mathrm{n}=1)$, or 29-mm $(\mathrm{n}=1)$ mechanical prosthesis.

Two late heart-related deaths occurred. A 2-year-old girl with severe congenital MR underwent $2 \mathrm{MV}$ repairs but finally required implantation of a mechanical prosthesis and died of valve thrombosis 1 year after MV replacement. A 12-month-old boy had had LVOTO-related MV disease. He had first undergone MV repair associated with aortic valvotomy. Four months later, he underwent a second MV repair associated with a complicated Ross procedure that required extracorporeal membrane oxygenation. He died of extracorporeal membrane oxygenation complications.

At the last follow-up visit, 15 patients $(14 \%)$ had moderate MR and 3 had moderate-to-severe or severe MR. Five patients $(4 \%)$ had a mean echocardiographic gradient $>10 \mathrm{~mm} \mathrm{Hg}$. All but 1 patient were New York Heart Association class I-II. Native valve preservation was obtained for $85 \%$ of the infants and $94 \%$ of those beyond infancy. The actuarial survival and actuarial 

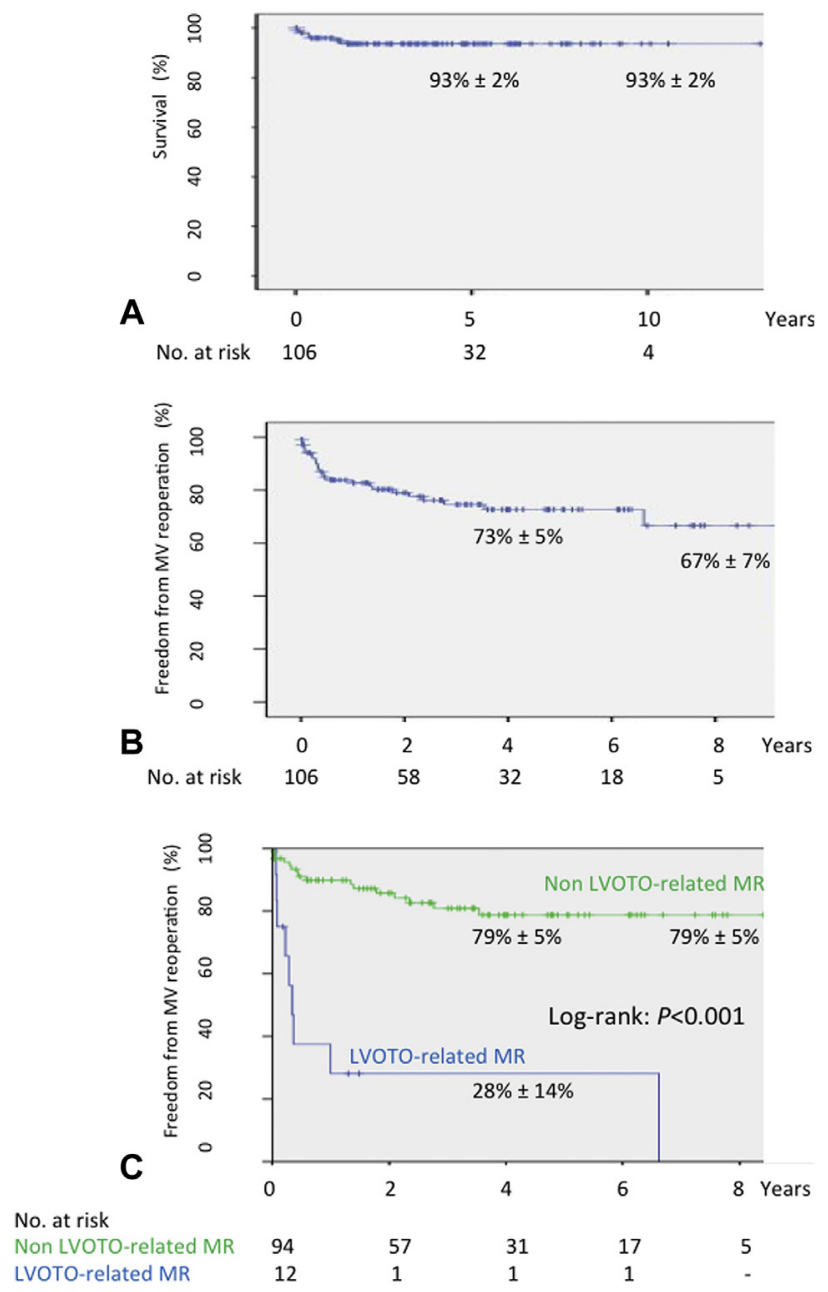

FIGURE 3. A, Actuarial survival. B, Overall actuarial freedom from mitral valve $(M V)$ reoperation, and $\mathrm{C}$, actuarial freedom from reoperation according to mitral insufficiency etiology. $M R$, Mitral regurgitation; LVOTO, left ventricular outflow tract obstruction.

freedom from MV reoperation and MV replacement according to MR etiology are presented in Figures 2 and 3. The actuarial survival, freedom from MV reoperation, and freedom from MV replacement rate was $93 \% \pm 2 \%$ at 10 years (Figure $2, A$ ), $67 \% \pm 7 \%$ at 8 years (Figure $2, B$ ), and $86 \% \pm 7 \%$ at 10 years (Figure 3, $A$ ), respectively. An LVOTO-related MR etiology was significantly associated with decreased actuarial freedom from MV reoperation and replacement (log-rank, $P<.001$; Figures $3, C$, and $4, B$ ).

\section{Outcomes and Etiologies}

The outcomes according to the mechanism and etiology of MI are summarized in Table 2. A Carpentier classification type III MI mechanism was significantly associated with an increased risk of MV replacement $(P=.02)$ and a postoperative transmitral mean echocardiographic gradient $>5 \mathrm{~mm} \mathrm{Hg}$ $(P=.02)$. An LVOTO-related MI etiology was statistically
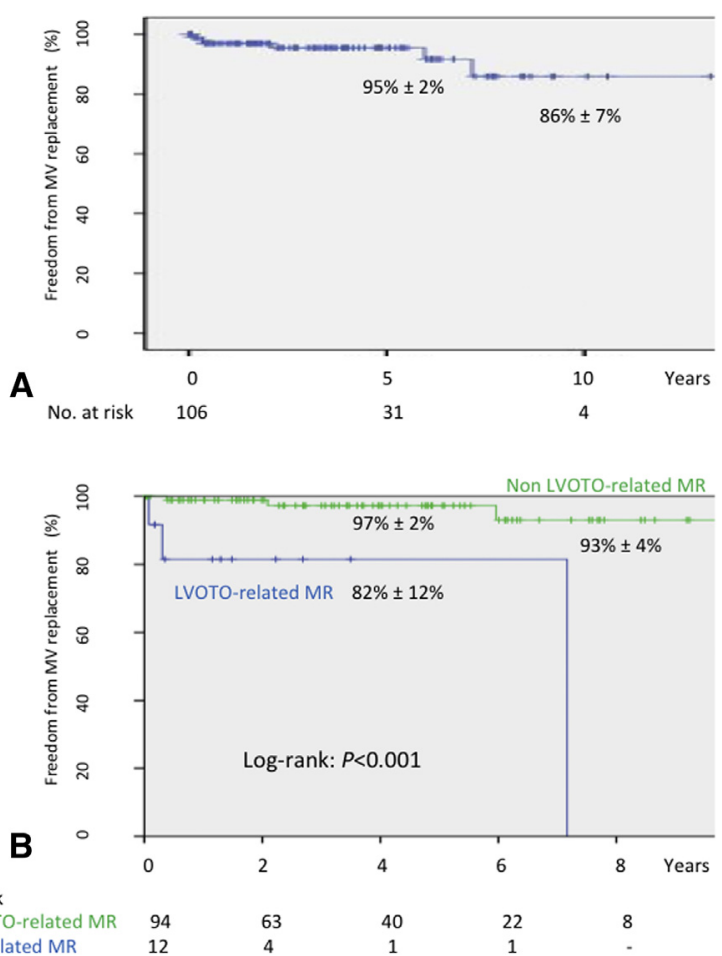

FIGURE 4. Overall actuarial freedom from (A) mitral valve $(M V)$ replacement and (B) actuarial freedom from replacement according to mitral insufficiency etiology. MR, Mitral regurgitation; LVOTO, left ventricular outflow tract obstruction.

associated with MV reoperation $(P<.001)$, MV replacement $(P=.01)$, residual MI $(P<.001)$, and a postoperative transmitral mean echocardiographic gradient $>5 \mathrm{~mm} \mathrm{Hg}(P=.005)$. In contrast, the presence of a mitral cleft seemed to be less prone to developing postoperative $\operatorname{MR}(P=.04)$.

\section{Risk Analysis}

The results of the univariate and multivariate analyses are presented in Table 3. An LVOTO-related etiology was an independent predictor of recurrent MR (odds ratio, 33; 95\% confidence interval [CI], 1.2-956; $P=.04)$, MV reoperation (hazard ratio [HR], 45; 95\% CI, 3-624; $P=.004$ ), and MV replacement (HR, 30; 95\% CI, 1.2-731; $P=.03$ ). The other independent predictors of MV reoperation were an associated preoperative transmitral mean echocardiographic gradient $>5 \mathrm{~mm} \mathrm{Hg}(\mathrm{HR}, 21 ; 95 \% \mathrm{CI}, 1.3-341 ; P=.03)$ and young age at surgery (HR, $1.21 ; 95 \% \mathrm{CI}, 1.1-1.4$; $P=.04)$. The MR grade did not significantly increase the risk of MV reoperation. However, MV reoperation, MV replacement, and young age at surgery were significantly associated with an increased risk of mortality on univariate analysis (Table 3 ).

\section{DISCUSSION}

The surgical options for MR in children include MV repair and MV replacement with mechanical prostheses. 
TABLE 3. Univariate and multivariate risk analyses for recurrent mitral regurgitation, transmitral gradient, reoperation, replacement, and mortality

\begin{tabular}{|c|c|c|}
\hline Endpoint & Univariate analysis & Multivariate analysis \\
\hline MR (grade II-III) & $\begin{array}{l}\text { Left heart obstruction-related MR }(P<.001) \\
\text { Associated mitral cleft }(P=.04) \text { (protective factor*) } \\
\text { Associated preoperative transmitral gradient }>5 \mathrm{~mm} \mathrm{Hg} \\
\quad(P=.02) \\
\text { Nonoptimal immediate result } \dagger(P=.01) \\
\text { Young age }(P<.001)\end{array}$ & $\begin{array}{l}\text { Left heart obstruction-related MR }(P=.04 ; \text { OR, } 33 \text {; } \\
\quad 95 \% \text { CI, 1.2-956) }\end{array}$ \\
\hline $\begin{array}{l}\text { Transmitral mean } \\
\text { echocardiographic } \\
\text { gradient }>5 \mathrm{~mm} \mathrm{Hg}\end{array}$ & $\begin{array}{l}\text { Left heart obstruction-related MR }(P=.005) \\
\text { Associated preoperative transmitral gradient }>5 \mathrm{~mm} \mathrm{Hg} \\
\quad(P=.004) \\
\text { Type III MR mechanism: } P=.02 \\
\text { Nonoptimal immediate result } \dagger(P=.007) \\
\text { Young age }(P<.001) \\
\text { Male gender }(P=.03)\end{array}$ & None \\
\hline MV reoperation & $\begin{array}{l}\text { Left heart obstruction-related } \mathrm{MR}(P<.001) \\
\text { Nonoptimal immediate result } \dagger(P=.01) \\
\text { Young age }(P<.001)\end{array}$ & $\begin{array}{l}\text { Left heart obstruction-related MR }(P=.004 ; \mathrm{HR}, 45 \text {; } \\
\quad 95 \% \mathrm{CI}, 3-624) \\
\text { Associated preoperative transmitral gradient } \\
\quad>5 \mathrm{~mm} \mathrm{Hg}(P=.03 ; \mathrm{HR}, 21 ; 95 \% \mathrm{CI}, 1.3-341) \\
\text { Young age }(P=.04 ; \mathrm{HR}, 1.21 ; 95 \% \mathrm{CI}, 1.1-1.4)\end{array}$ \\
\hline MV replacement & $\begin{array}{l}\text { Left heart obstruction-related MR }(P=.01) \\
\text { Associated preoperative transmitral gradient }>5 \mathrm{~mm} \mathrm{Hg} \\
\quad(P=.01) \\
\text { Type III MR mechanism }(P=.02) \\
\text { Leaflet augmentation by patch }(P=.03) \\
\text { Quadrangular resection of posterior leaflet }(P=.003) \\
\text { Increased TMG at discharge }(P=.009)\end{array}$ & $\begin{array}{l}\text { Left heart obstruction-related MR }(P=.03 ; \mathrm{HR}, 30 \\
\quad 95 \% \mathrm{CI}, 1.2-731)\end{array}$ \\
\hline Mortality & $\begin{array}{l}\text { Preoperative NYHA class }(P=.001) \\
\text { Papillary muscle hypoplasia }(P=.01) \\
\text { Immediate postoperative severe MR }(P=.001) \\
\text { MV reoperation }(P=.03) \\
\text { MV replacement }(P=.02) \\
\text { Long stay in ICU }(P<.001) \\
\text { Young age }(P<.001)\end{array}$ & None \\
\hline
\end{tabular}

$M R$, Mitral regurgitation; $O R$, odds ratio; $C I$, confidence interval; $M V$, mitral valve; $H R$, hazard ratio; NYHA, New York Heart Association; TMG, trans-mitral gradient; $I C U$, intensive care unit. *Isolated mitral cleft was a protective factor; all other factors were risk factors. $\dagger$ Nonoptimal immediate postoperative result corresponding to MR grade II-III or mean echocardiographic gradient $>5 \mathrm{~mm} \mathrm{Hg}$ on immediate postoperative transesophageal echocardiogram.

MV mechanical replacement in children has had numerous major drawbacks, including the absence of annular growth and the subsequent need for mitral reoperation, difficult management of anticoagulant therapy for children, a potential patient-prosthesis mismatch exposing patients to high early and late mortality in children, and the deleterious effect of a mechanical MV prosthesis on LV function. ${ }^{13-15}$ To avoid mechanical prostheses and their poor outcomes, we considered MV repair as the reference standard, aiming more for the restoration of a durable functional anatomy than a time gain. The "nothing else but repair" strategy was adopted and showed, usually at the cost of a considerable rate of reoperation, promising outcomes with a preserved native valve.

MV repair in children has been considered one of the least reproducible and most difficult to teach cardiac surgical procedures. This has been because of the high variability in MV anatomy, MV dysfunctional mechanisms, lesion etiology, the unavailability of prosthetic ring devices, and differing surgical indications and techniques. We have reported, through this relatively significant series, our repair-oriented strategy in a standardized manner for pedagogic purposes and reproducibility. The tools we have described, with their own indication, represent the true skeleton of the strategy supported by the reported outcomes. Improving the leaflet mobility through aggressive subvalvular apparatus debridement is of major importance and will determine the success of the repair in many cases. Annuloplasty, whose role is to segmentally reduce the dilated annulus, stabilize the repair, ${ }^{8}$ and increase the height of the posterior leaflet coaptation surface area, ${ }^{9}$ seems mandatory for all MV repairs for MR, even in patients with an isolated mitral cleft. Pericardial patch augmentation of the leaflets had been demonstrated as a simple, safe, and efficient technique in MV reconstruction by Carpentier's group, in both adult 
and pediatric patients. ${ }^{8,16,17}$ In addition to increasing the leaflet surface and improving leaflet coaptation in patients with MR with valvular tissue lacking, this surgical technique also allows one to limit the need for excessive annular plication in young patients. In the beginning of our experience, posterior leaflet augmentation appeared to be more appropriate. However, the commissure-tocommissure enlargement of the posterior leaflet resulted in significant postoperative transvalvular gradients, particularly in younger patients. The cause of this complication was obviously the "gutter" effect created by the disappearance of both scallops of the posterior leaflet. Preservation of at least 1 (the anterior would seem to be more appropriate) of these would seem mandatory if the repair should include posterior leaflet augmentation. The patch used was almost always autologous pericardium. Glutaraldehyde treatment was performed in primary procedures, with fresh pericardium preferred in reoperations because of the fibrous thickening in the latter. In 2 patients, heterologous glutaraldehyde-treated pericardium was used because autologous pericardium was unavailable. The behavior of autologous pericardium as leaflet tissue was satisfactory in most patients; however, the anterior leaflet augmentation patch composed of glutaraldehyde-treated autologous pericardium led to significant fibrocalcifications requiring a reoperation in 1 of 23 patients $(4 \%)$. Oppido and colleagues $^{8}$ did not report such an evolution of an augmentation patch composed of the same glutaraldehyde-treated material. The pejorative evolution of this patch might be explained by an enhanced individual susceptibility of some patients to develop calcifications of the autologous pericardium. The autologous pericardium had initially been treated with glutaraldehyde in our patient and had been replaced by fresh pericardium at reoperation, with a favorable outcome at 3 postoperative years.

The midterm outcomes of this strategy in children with severe MR have been very satisfactory, with an actuarial survival of $93 \% \pm 2 \%$ at 10 years, freedom from MV reoperation of $67 \% \pm 7 \%$ at 8 years, and freedom from MV replacement of $86 \% \pm 7 \%$ at 10 years. The present series reflects the outcomes of our MV repair strategy in the whole population of children who underwent surgery for severe MR compared with other studies that focused on specific functional subgroups of $\mathrm{MR}^{9}$ or a mixed population of MR and mitral stenosis. ${ }^{8}$ Our standardized strategy led to conservation of the native valve in $85 \%$ of patients who required the procedure in infancy and in $94 \%$ of those treated at a later age. However, such results were obtained in some patients at the cost of multiple reoperations.

The multivariate risk analysis showed the major pejorative role played by the LVOTO-related etiology of MR. This etiology was an independent and clinically significant risk factor for recurrent MR, MV reoperation, and MV replacement. Other independent predictors of MV reoperation were associated preoperative mitral stenosis and young age at surgery. To our knowledge, only 1 previous study $^{8}$ had tried to determine the multivariate risk factors for pejorative outcomes after MV repair in children. However, that study, which included 71 patients, only suggested that residual postoperative valvular dysfunction could lead to an increased risk of reoperation $(P=.07)$.

In infants born with subaortic-aortic valvular stenosis, with or without aortic arch obstruction, MV dysfunction is not uncommon, resulting in a clinical and surgical challenge. ${ }^{10}$ The major pejorative role played by the LVOTO-related etiology of MR could be because the MR in this pathologic condition is only the marker of a global disease of the left heart. Even if the LVOTO has been treated surgically, the spontaneous evolution of the ventricular geometry would negatively affect the outcome of the MV repair: the deterioration of good early functional results at midterm follow-up was not uncommon. Nevertheless, we have continued to advocate the use of our strategy for this challenging subgroup in lieu of a more satisfactory alternative.

We have also demonstrated that young age at surgery was an independent predictor of MV reoperation. This finding has been suggested but not proved by previous studies. ${ }^{8,9}$

\section{Study Limitations}

The major limitation of the present study was its retrospective design. The possible bias related to the effect of the surgical era on the evaluation of outcomes was very limited, because the surgical strategy was quite constant during the study period. The heterogeneity of the patients and their anatomic variants were taken into account in the multivariate risk analysis. A low cutoff of $5 \mathrm{~mm} \mathrm{Hg}$ was chosen for evaluation of the transmitral mean echocardiographic gradient in the risk analysis to detect the risk factors for early postoperative mitral stenosis. The bias owing to a very small number of patients with extremely unfavorable anatomy and/or clinical condition who underwent valve replacement with poor outcomes should also be considered.

\section{CONCLUSIONS}

The present 3-step standardized and reproducible MV repair strategy achieved satisfactory functional results in infants and children with severe MR, avoiding MV replacement, but at the cost of reoperations. Mortality, MV reoperation, MV replacement, and recurrent MR rates at the last follow-up examination was $4 \%, 23 \%, 5 \%$, and $17 \%$, respectively. The actuarial survival and freedom from MV replacement was $93 \% \pm 2 \%$ and $86 \% \pm 7 \%$ at 10 years, respectively. An LVOTO-related etiology was the main independent predictor of recurrent MR, MV reoperation, and MV replacement. Other independent 
predictors of MV reoperation were associated preoperative mitral stenosis and young age at surgery. Additional followup data appear mandatory, in particular to investigate the outcomes of the autologous pericardium substituting for the lacking leaflet tissue.

\section{References}

1. Uva MS, Galletti L, Gayet FL, Piot D, Serraf A, Bruniaux J, et al. Surgery for congenital mitral valve disease in the first year of life. J Thorac Cardiovasc Surg. 1995;109:164-74.

2. Chauvaud S, Fuzellier JF, Houel R, Berrebi A, Mihaileanu S, Carpentier A. Reconstructive surgery in congenital mitral valve insufficiency (Carpentier's techniques): long-term results. J Thorac Cardiovasc Surg. 1998;115:84-92.

3. Zias EA, Mavroudis C, Backer CL, Kohr LM, Gotteiner NI, Rocchini AP. Surgical repair of the congenitally malformed mitral valve in infants and children. Ann Thorac Surg. 1998;66:1551-9.

4. Komoda T, Huebler M, Berger F, Hetzer R. Growth of mitral annulus in the pediatric patient after suture annuloplasty of the entire posterior mitral annulus. Interact Cardiovasc Thorac Surg. 2009;9:354-6.

5. Delmo Walter EM, Siniawski H, Ovroutski S, Hetzer R. Mitral valve growth after posterior annular stabilization with untreated autologous pericardial strip in children with mitral valve insufficiency. Ann Thorac Surg. 2010;90:1577-85.

6. Hetzer R, Delmo Walter EB, Hubler M, Alexi-Meskishvili V, Weng Y, Nagdyman N, et al. Modified surgical techniques and long-term outcome of mitral valve reconstruction in 111 children. Ann Thorac Surg. 2008;86:604-13.

7. Stellin G, Padalino M, Milanesi O, Vida V, Favaro A, Rubino M, et al. Repair of congenital mitral valve dysplasia in infants and children: is it always possible? Eur J Cardiothorac Surg. 2000;18:74-82.
8. Oppido G, Davies B, McMullan DM, Cochrane AD, Cheung MM, d'Udekem Y, et al. Surgical treatment of congenital mitral valve disease: midterm results of a repair-oriented policy. J Thorac Cardiovasc Surg. 2008;135:1313-20.

9. Delmo Walter EM, Komoda T, Siniawski H, Hetzer R. Surgical reconstruction techniques for mitral valve insufficiency from lesions with restricted leaflet motion in infants and children. J Thorac Cardiovasc Surg. 2012;143:S48-53.

10. Delmo Walter EM, Van Praagh R, Miera O, Hetzer R. Repair of left ventricular inflow tract lesions in Shone's anomaly: valve growth and long-term outcome. Ann Thorac Surg. 2013;95:948-55.

11. Delmo Walter EM, Komoda T, Siniawski H, Hetzer R. Long-term surgical outcome of mitral valve repair in infants and children with Shone's anomaly. Eur J Cardiothorac Surg. 2013;43:473-81.

12. Lancellotti P, Moura L, Pierard LA, Agricola E, Popescu BA, Tribouilloy C, et al. European Association of Echocardiography recommendations for the assessment of valvular regurgitation. Part 2: mitral and tricuspid regurgitation (native valve disease). Eur J Echocardiogr. 2010;11:307-32.

13. Kojori F, Chen R, Caldarone CA, Merklinger SL, Azakie A, Williams WG, et al Outcomes of mitral valve replacement in children: a competing-risks analysis J Thorac Cardiovasc Surg. 2004;128:703-9.

14. Caldarone CA, Raghuveer G, Hills CB, Atkins DL, Burns TL, Behrendt DM, et al. Long-term survival after mitral valve replacement in children aged $<5$ years: a multi-institutional study. Circulation. 2001;104:I143-7.

15. Gunther T, Mazzitelli D, Schreiber C, Wottke M, Paek SU, Meisner H, et al. Mitral-valve replacement in children under 6 years of age. Eur J Cardiothorac Surg. 2000; 17:426-30.

16. Chauvaud S, Jebara V, Chachques JC, el Asmar B, Mihaileanu S, Perier P, et al. Valve extension with glutaraldehyde-preserved autologous pericardium: results in mitral valve repair. J Thorac Cardiovasc Surg. 1991;102:171-7.

17. Acar C, de Ibarra JS, Lansac E. Anterior leaflet augmentation with autologous pericardium for mitral repair in rheumatic valve insufficiency. $J$ Heart Valve Dis. 2004;13:741-6. 